\title{
Technological Aspect of Processing Maps for the AA2099 Alloy
}

\author{
Aneta Lukaszek-Sołek
}

Received: 27 March 2014/Revised: 5 May 2014/Published online: 9 October 2014

(C) The Chinese Society for Metals and Springer-Verlag Berlin Heidelberg 2014

\begin{abstract}
Results of an experimental and modelling study of forming processes in the AA2099 Al-Cu-Li alloy, for a wide range of temperatures, strains and strain rates, are presented. The analyses are based on tensile testing at $20{ }^{\circ} \mathrm{C}$ at a strain rate of $0.02 \mathrm{~s}^{-1}$ and uniaxial compression testing in the temperature range $400-550{ }^{\circ} \mathrm{C}$ at strain rates ranging from 0.001 to $100 \mathrm{~s}^{-1}$, for constant values of true strain of 0.5 and 0.9 . The stability of plastic deformation and its relationship with a sensitivity of stress to strain rate are considered. The power dissipation efficiency coefficient, $\eta(\%)$, and the flow instability parameter, $\xi \leq 0$, were determined. The complex processing maps for hot working were determined and quantified, including process frames for basic forging processes: conventional forging and for near-superplastic and isothermal conditions. A significant aspect is the convergence of power dissipation when passing through the $500{ }^{\circ} \mathrm{C}$ peak. Deformation, temperature and strain-rate-dependent microstructures at $500{ }^{\circ} \mathrm{C}$ for strain rates of $0.1,1,10$ and $100 \mathrm{~s}^{-1}$ are described and analysed for the conventional die forging process frame, corresponding to $465-523{ }^{\circ} \mathrm{C}$ and strain rates of $50-100 \mathrm{~s}^{-1}$.
\end{abstract}

\section{KEY WORDS: Al-Cu-Li alloy; Power dissipation efficiency; Processing maps; Microstructure; Hot} deformation

\section{Introduction}

Important features of AA2099, an alloy of the latest third generation [1-4], based on phase equilibrium system of Al$\mathrm{Cu}-\mathrm{Li}-\mathrm{Zn}-\mathrm{Mg}$, include high specific strength, high rigidity, high shock resistance and high fracture toughness $K_{\mathrm{IC}}[2,5,6]$. Such alloys find wide industrial applications in aerospace and armaments industries and are valuable replacements for conventional alloys in applications requiring high thermal conductivity and dynamic loading resistance. Another

Available online at http://link.springer.com/journal/40195

A. Łukaszek-Sołek ( $\square$ )

Faculty of Metals Engineering and Industrial Computer Science,

AGH University of Science and Technology, Av. Mickiewicza

30, 30-059 Krakow, Poland

e-mail: anetasolek@gmail.com important feature is a fine-grained compact fibrous structure without internal defects, which increases strength and fatigue limit and provides high surface quality after hot working. To find the optimum processing parameters, it is important to evaluate the material's deformation behaviour in a wide range of temperatures, strain rates and strains. Based on isothermal uniaxial compression testing and microstructural examination, processing maps [7-10] are a useful tool for the optimization of hot working processes and evaluation of workability. Such maps, reported for numerous alloys [8, 1117], serve as a modern technique for improving the description of thermomechanical processing and, as a consequence, the design of hot working processes. Luo et al. [17] exhibited the effect of strain (in the range of 0.2-0.7) on the grain size, the efficiency of power dissipation and the instability parameter for $\mathrm{Ti}-6 \mathrm{Al}-4 \mathrm{~V}$, Ti-5.6Al-4.8Sn-2Zr and $\mathrm{Ti}-10 \mathrm{~V}-4.5 \mathrm{Fe}-$ $1.5 \mathrm{Al}$ alloys. Moreover, the researchers constructed P-maps for the investigated titanium alloys at a series of strains. 
Through careful working out of processing maps and microstructural changes [18-22], establishment of the optimum technological process parameters becomes possible, including taking account of the influence of grain size on the properties of the alloy [23]. Cepeda-Jimez et al. [18] established the working regime for the forming of $\mathrm{Al} 2024$ alloy in the temperature range of $360-410{ }^{\circ} \mathrm{C}$ and for strain rates of $2.1-4.5 \mathrm{~s}^{-1}(\eta=13 \%)$. It was emphasized that the decrease of temperature to $278-315^{\circ} \mathrm{C}$, especially at high strain rates, increases the risk of flow instability. Moreover, these maps can be a basis for combining experimental results with numerical modelling [24-27]. Liu et al. [24, 25] analysed the workability of AZ31B magnesium alloy, applying the combination of processing maps and FE simulation. In this investigation, the maps were based on the method of dynamic material modelling (DMM) [8-10, 28, 29], as a comprehensive approach to the correlation of constitutive changes with microstructural changes, material flow instability [30, 31] and hot workability $[32,33]$.

\section{Experimental}

The material used in the present study was the AA2099T83 alloy of chemical composition and mechanical properties are given in Tables 1 and 2 . The alloy was delivered in the form of a bar of $100 \mathrm{~mm}$ diameter and its lamellar fibrous microstructure is presented in Fig. 1. The micrographs (Fig. 1a, b) of a longitudinal section show grains of similar size, elongated in the extrusion direction, of microhardness $180 \mathrm{HV}$. Highly equiaxed grains are observed on the transverse section (Fig. 1c, d).

In order to establish process maps for the investigated material, mechanical testing was carried out using Gleeble 3800 simulator in the temperature range $400-550{ }^{\circ} \mathrm{C}$. Specimens, of $10 \mathrm{~mm}$ diameter and $12 \mathrm{~mm}$ height, machined from the initial material, were heated at $2.5^{\circ} \mathrm{C} / \mathrm{s}$ up to the specified temperature and then subjected to uniaxial compression testing. Deformation was carried out up to the constant final true strain value of 0.9 at strain rates between 0.001 and $100 \mathrm{~s}^{-1}$. The inverse method, described in details by Szeliga et al. [34], was applied to interpret the results of the axisymmetric compression tests. The microstructures were examined using Leica DM 4000M optical microscope and a Hitachi SU-70 scanning electron microscope, using the back scatter electrons (BSE) technique. Microhardness measurements were performed on an Innovatest device, applying a load of 1.0 N.

The complex processing maps for AA2099 alloy were drawn and structurally energetically quantified by the DMM method [35], with the application of computational engineering and microstructural analyses, for true strain values of 0.5 and 0.9. Basing on the assessment of processing maps, flow instability parameter and microstructural analysis, the
Table 1 Chemical composition (wt\%) of the investigated AA2099 alloy

\begin{tabular}{lllllllll}
\hline $\mathrm{Cu}$ & $\mathrm{Li}$ & $\mathrm{Zn}$ & $\mathrm{Mg}$ & $\mathrm{Mn}$ & $\mathrm{Zr}$ & $\mathrm{Ti}$ & $\mathrm{Fe}$ & $\mathrm{Al}$ \\
\hline 2.6 & 1.8 & 0.7 & 0.29 & 0.3 & 0.1 & 0.03 & 0.02 & Bal. \\
\hline
\end{tabular}

Table 2 Properties of AA2099 alloy

\begin{tabular}{|c|c|c|c|c|c|c|}
\hline $\begin{array}{l}\rho \\
\left(\mathrm{g} / \mathrm{cm}^{3}\right)\end{array}$ & $\begin{array}{l}R_{\mathrm{p} 0.2} \\
\left(\mathrm{~N} / \mathrm{mm}^{2}\right)\end{array}$ & $\begin{array}{l}R_{\mathrm{m}} \\
\left(\mathrm{N} / \mathrm{mm}^{2}\right)\end{array}$ & $\begin{array}{l}\mathrm{A}_{5} \\
(\%)\end{array}$ & $\begin{array}{l}Z_{\mathrm{z}} \\
(\%)\end{array}$ & $E(\mathrm{GPa})$ & HB \\
\hline 2.63 & 596.9 & 615 & 5.8 & 9.7 & 83 & 157 \\
\hline
\end{tabular}

most favourable regions (process frames-domains) corresponding to hot die forging processes were determined. The regions which should be excluded when designing the technology were indicated.

\section{Results and Discussion}

\subsection{Stress-Strain Behaviour}

Examples of flow curves for temperatures of 450 and $500{ }^{\circ} \mathrm{C}$ are shown in Fig. 2. The flow curves show a characteristic initial increase of stress, up to a maximum occurring at a very small strain of about 0.05 (except for the strain rate of $100 \mathrm{~s}^{-1}$ where the increase of $\sigma_{\mathrm{pl}}$ is limited to much smaller strains). For strain range $0.2-0.9$, at strain rates of $0.001-1 \mathrm{~s}^{-1}$, there is then a progressive moderate decrease of the flow stress. At the process temperature of $500{ }^{\circ} \mathrm{C}$ and strain rates of $0.001-0.1 \mathrm{~s}^{-1}$, a distinct lowering of deformation resistance is observed. Differences between flow curves may result from the effect of strain rate on the evolution of banded fibrous structure of fine grains. Low values of flow stress at strain rates of $0.001-0.1 \mathrm{~s}^{-1}$ most probably testify to near-superplastic properties of the alloy [36, 37]. For the strain rate of $100 \mathrm{~s}^{-1}$, at temperatures of 450 and $500{ }^{\circ} \mathrm{C}$ (Fig. 2), the intensive decrease of the flow stress may testify to a distinct loss of precipitation hardening occurring at a small strain of about 0.005 and proceeding up to the strain of 0.9 . The character of this variation is nonlinear and can confirm a slight anisotropy of the specimens being tested.

\subsection{Strain Rate Sensitivity}

The relationship between flow stress and strain rate can be expressed in the form of an exponential function:

$\sigma=K(\dot{\varepsilon})^{m}$

where $K$ is material constant and $m$ is strain rate sensitivity exponent, most often defined by the following equation [26-28, 30, 32, 35]: 

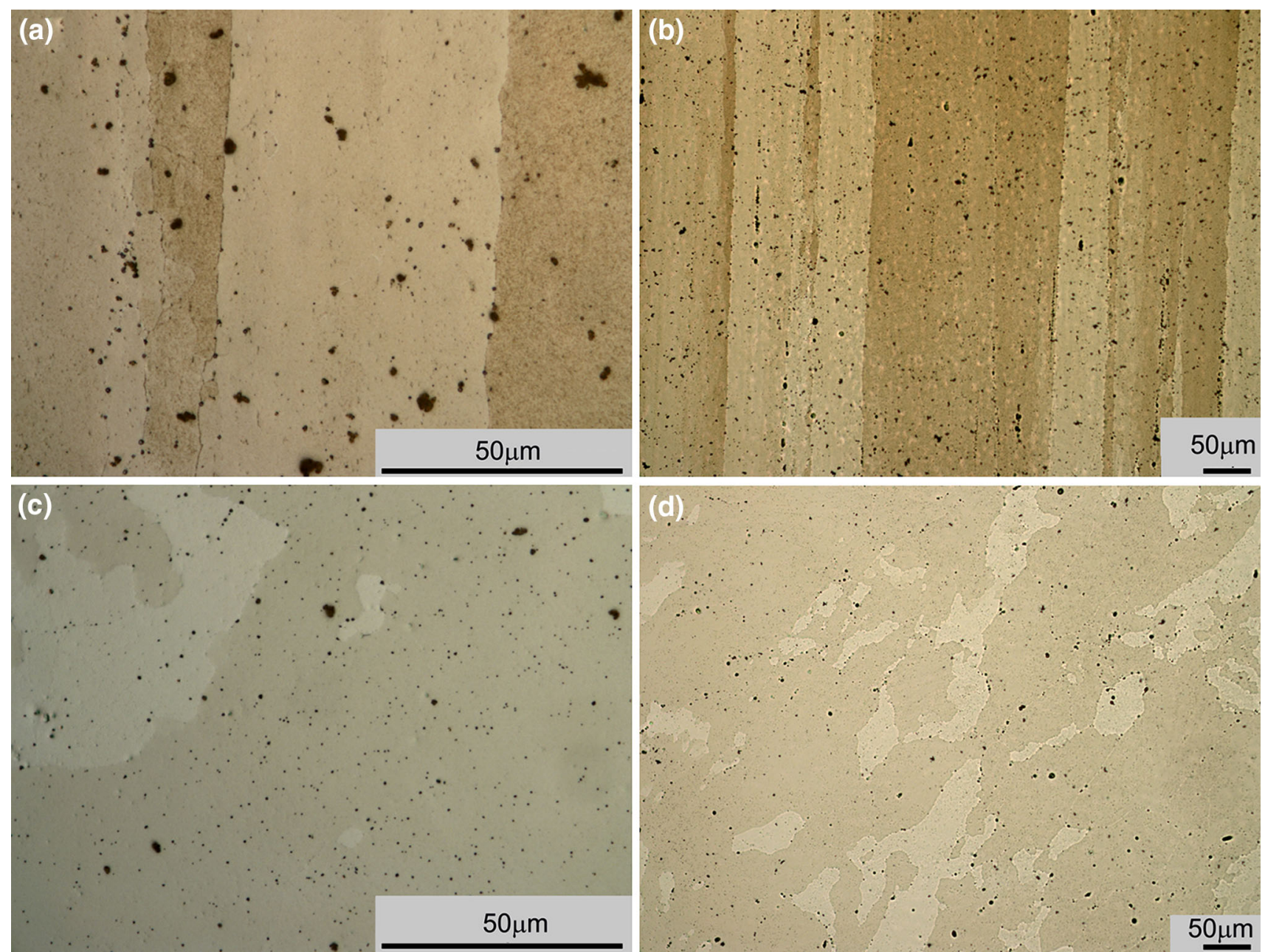

Fig. 1 Microstructure of the investigated alloy (as-delivered conditions): a, b longitudinal section, $\mathbf{c}, \mathbf{d}$ transverse section of a bar
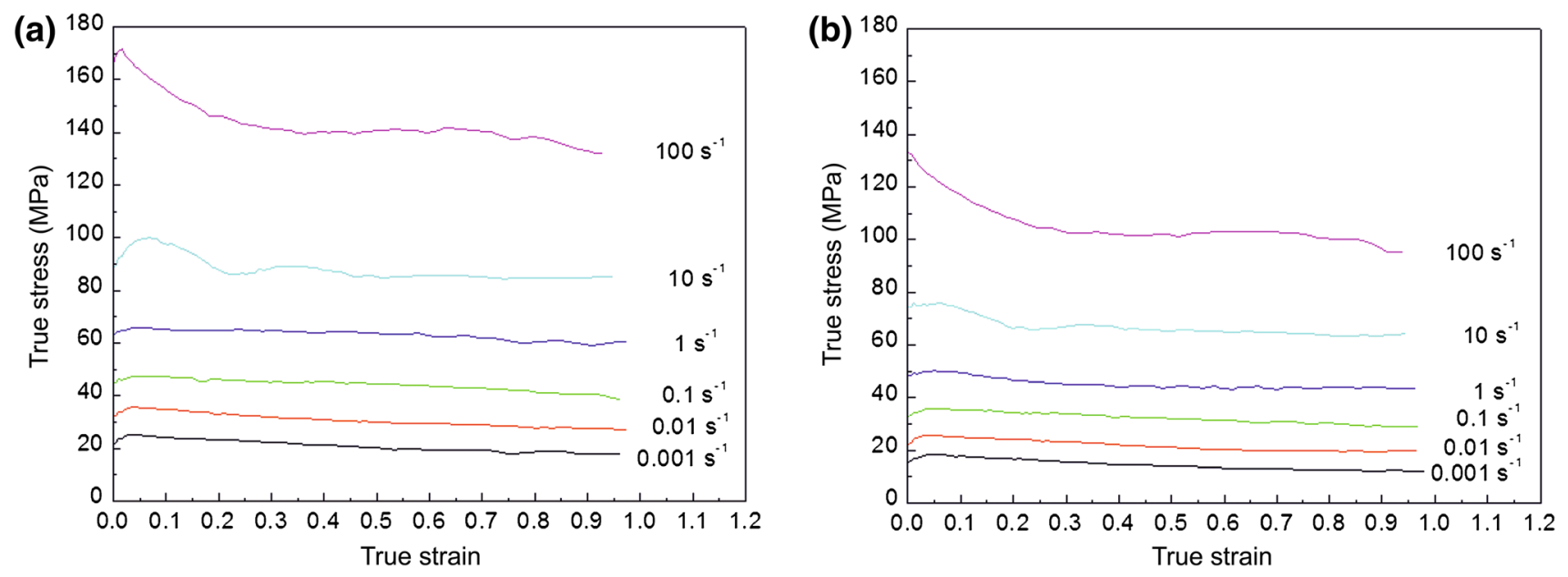

Fig. 2 Stress-strain curves of AA2099 alloy obtained at different strain rates and temperatures of $450{ }^{\circ} \mathrm{C}$ a and $500{ }^{\circ} \mathrm{C} \mathbf{b}$

$m=\left(\frac{\partial \log \sigma}{\partial \log \dot{\varepsilon}}\right)_{T, \varepsilon}$.

This exponent can be determined from the relationship $\log \sigma$ versus $\log \dot{\varepsilon}$, for a specific constant strain value $(\varepsilon=0.5,0.9)$ and varying temperature.

In order to determine the relationship between $\log \sigma$ and $\log \dot{\varepsilon}$, analytical form of the model was chosen, based on 

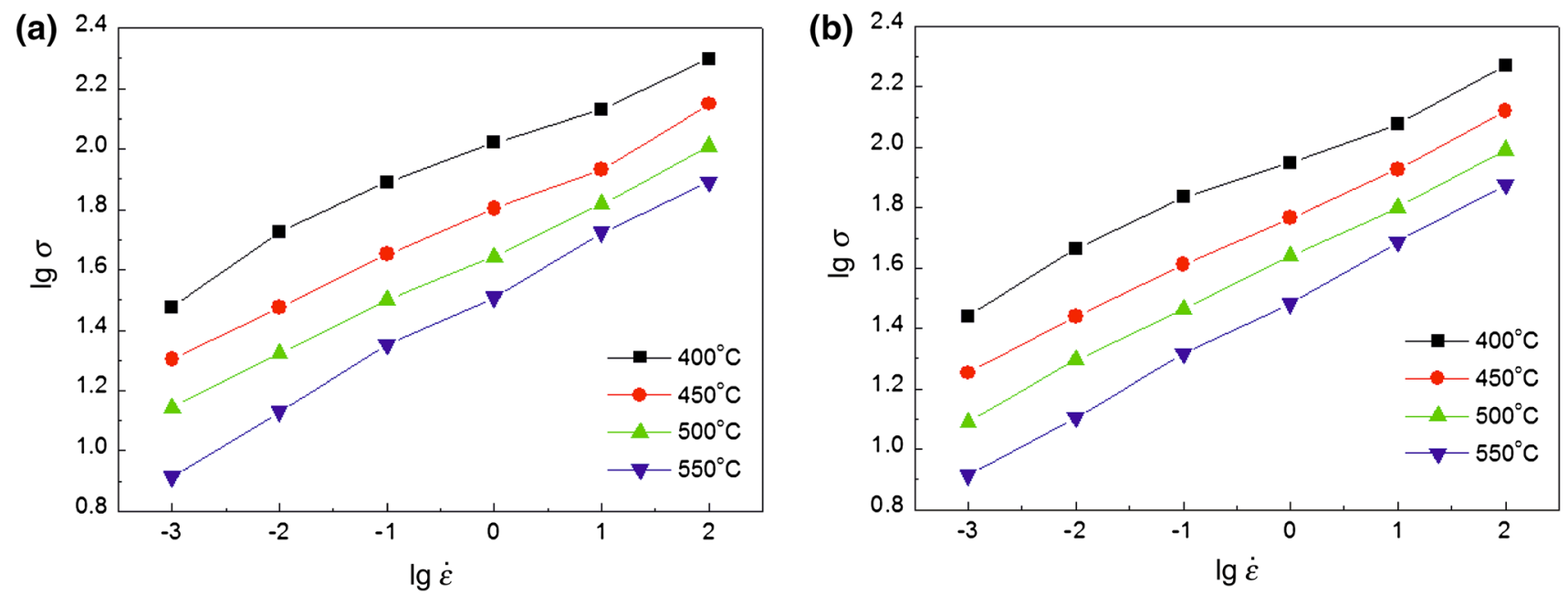

Fig. 3 Relations between $\log \sigma$ and $\log \dot{\varepsilon}$ for true strain of $0.5 \mathbf{a}$ and $0.9 \mathbf{b}$

the results of observation of scatter of empirical points for each potential variable (Fig. 3), assuming constant strain value and varying temperature. As a consequence, a polynomial regression function was obtained, which can be generally described by the equation:

$\log \sigma=a+b \log \dot{\varepsilon}+c(\log \dot{\varepsilon})^{2}+d(\log \dot{\varepsilon})^{3}$.

As a result, the models of polynomial regression (Eq. (3)) based on the statistical equation were obtained for each of the analysed temperatures, with $(a, b, c, d)$ being the structural parameters of a polynomial regression function. These parameters were statistically estimated based on empirical results from the observation of random test (structural parameters examples are shown in Table 3). For the formulated regression functions (Eq. (3)), the analysis of the degree of fitting of a model to the data was performed. The analysis consists of a verification of the correctness of a selected model type and checking the deviation of empirical $y_{i}$ values of assignable variable from theoretical $\hat{y}_{i}$ values obtained for the estimated model. The evaluated coefficient of determination $R^{2}$ is better than 0.99 for each curve. This means that over $99 \%$ of variability of the assignable variable was assigned by the given model (Eq. (3)).

Strain rate sensitivity exponent $(m)$ can be determined as the first derivative calculated from a polynomial regression function (Eq. (3)) and expressed by the general formula:

$m=b+2 c \log \dot{\varepsilon}+3 d(\log \dot{\varepsilon})^{2}$,

where $b, c$ and $d$ are the structural parameters.

Figure 4 shows the changes of exponent $m$, within the range of $0.12-0.29$, with strain rate and temperature. It is seen to vary parabolically for $400{ }^{\circ} \mathrm{C}$ (perfect regularity) to $550{ }^{\circ} \mathrm{C}$ (flattened shape, close to straight line, with a deviation at the axis of symmetry). Such character of variations suggests that the material is less sensitive to strain rate at the
Table 3 Examples for statistically estimated structural parameters of a polynomial regression function (Eq. (3)) for true strain of 0.9

\begin{tabular}{lll}
\hline Parameters & \multicolumn{2}{l}{ Temperature $\left({ }^{\circ} \mathrm{C}\right)$} \\
\cline { 2 - 3 } & 400 & 550 \\
\hline$a$ & 1.9469 & 1.4967 \\
$b$ & 0.1295 & 0.1890 \\
$c$ & 0.0038 & 0.0016 \\
$d$ & 0.0059 & 0.0001
\end{tabular}

temperature of $550{ }^{\circ} \mathrm{C}$, compared to other analysed temperatures. It can be noticed that there are two ranges, the first, for low strain rates $\left(\dot{\varepsilon}_{1}=0.001-0.04 \mathrm{~s}^{-1}\right)$, and the second for medium and high strain rates $\left(\dot{\varepsilon}_{2}=0.04-100 \mathrm{~s}^{-1}\right)$.

In the first range, for the process temperature of $400{ }^{\circ} \mathrm{C}$, parameter $m$ varies along the half of the parabola, showing a dynamic decrease from 0.29 to 0.12 , with strain rate increasing from 0.001 to $0.01 \mathrm{~s}^{-1}$. As the temperature rises, the value of $m$ is restricted to the range of $0.23-0.17$, producing the gradient of $\Delta=0.06$ for $500{ }^{\circ} \mathrm{C}$. At $550{ }^{\circ} \mathrm{C}$, the parameter $m$ stays within a very narrow range of $0.205-0.19(\Delta=0.015)$. Slight gradual changes of the $m$ parameter for $500-550{ }^{\circ} \mathrm{C}$ and strain rate $\dot{\varepsilon}_{1}=0.001-0.04 \mathrm{~s}^{-1}$ indicate high workability of the material. In the second range, $m$ exhibits the ascending relationship with the process temperature, with a characteristic intersection of curves at about $60 \mathrm{~s}^{-1}$. A distinct flattening of a parabolic curve at $500-550{ }^{\circ} \mathrm{C}$ is a confirmation for the optimum temperature for satisfactory effectiveness of plastic working of a material at strain rates of $1-60 \mathrm{~s}^{-1}$. Both halves of a parabola (Fig. 4a) show sharply outlined profile and similar interpretation of $m$, in relation to Fig. $4 \mathrm{~b}$, also confirming $500{ }^{\circ} \mathrm{C}$ as suitable for conventional forging of the AA2099 alloy. 

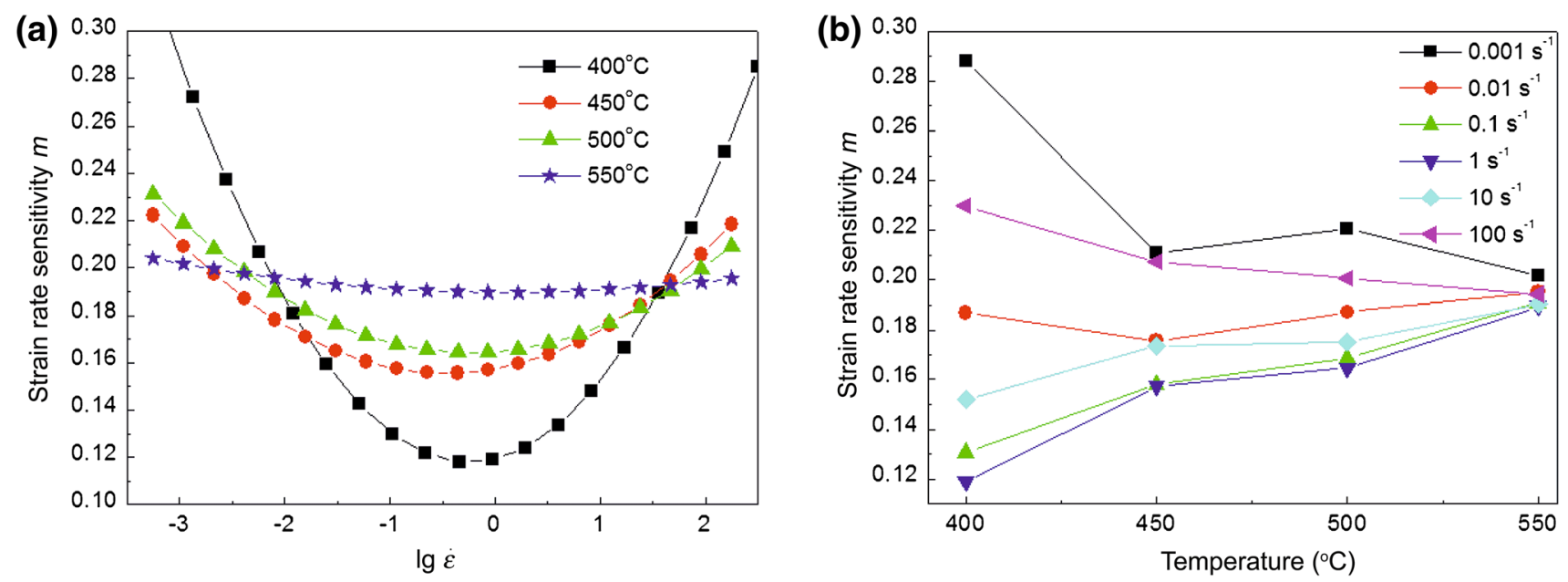

Fig. 4 Changes of strain rate sensitivity exponent $(m)$ : a as a function of $\log (\dot{\varepsilon})$, for the analysed temperatures and $\mathbf{b}$ as a function of temperature, at constant strain of 0.9

As shown in Fig. $4 \mathrm{~b}$, for $400-450{ }^{\circ} \mathrm{C}$, the parameter $m$ decreases for strain rates $\dot{\varepsilon}=0.001-0.01 \mathrm{~s}^{-1}$ and $100 \mathrm{~s}^{-1}$ and increases for $\dot{\varepsilon}=0.1$ and $10 \mathrm{~s}^{-1}$. At $500{ }^{\circ} \mathrm{C}$, a characteristic peak of $m$ value is observed and at $550{ }^{\circ} \mathrm{C}$ the convergence of $m$ parameter narrows to the range from 0.2 for $\dot{\varepsilon}=0.001 \mathrm{~s}^{-1}$ to 0.18 for $\dot{\varepsilon}=0.1-1 \mathrm{~s}^{-1}$, thus giving quite small gradient of $\Delta=0.02$.

\subsection{Processing Maps}

In DMM [8-10, 26, 28, 35, 38, 39], the unit power $(P)$ absorbed by the material during plastic working is expressed:

$P=\sigma \cdot \dot{\varepsilon}=G+J=\int_{0}^{\dot{\varepsilon}} \sigma_{\mathrm{p}} \mathrm{d} \dot{\varepsilon}+\int_{0}^{\sigma} \dot{\varepsilon} \mathrm{d} \sigma$,

where $G$ is dissipator content (represents the power dissipated by plastic work), $J$ is dissipator co-content (related to metallurgical processes/mechanisms proceeding dynamically with power dissipation). These processes may include dynamic recovery, dynamic recrystallization, internal fracture (void formation, wedge cracking), dissolution or growth of particles or phases under dynamic conditions, dynamic spheroidisation of acicular structures, deformation-induced phase transformation or precipitation under dynamic conditions [13, 25, 28, 31]. Figure 5 presents $J$ as a function of temperature and strain rate at constant strains, according to the formula $[8,9,13$, 25, 28]:

$J=\int_{0}^{\sigma} \dot{\varepsilon} \mathrm{d} \sigma=\frac{\sigma \cdot \dot{\varepsilon} \cdot m}{m+1}$

where $\varepsilon$ is constant strain value; $\dot{\varepsilon}$ is strain rate, $\mathrm{s}^{-1} ; \sigma$ is flow stress, $\mathrm{MPa} ; m$ is strain rate sensitivity exponent.

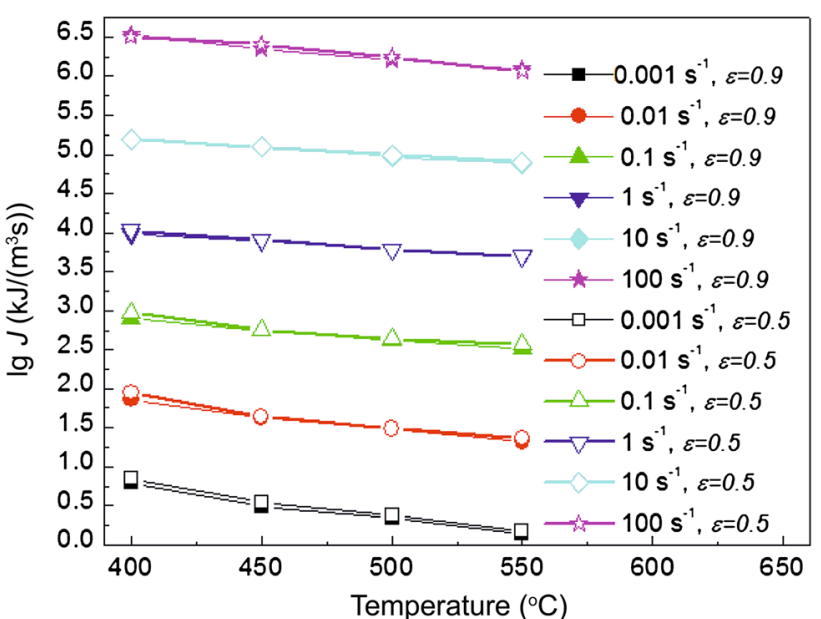

Fig. 5 Variations of $J$ co-content as a function of temperature, strain rate and constant strain value

Figure 6 presents the related metallographic observations, illustrating microstructure refinement with numerous precipitates and intermetallic phases. $J$ co-content component was found to decrease gradually, close to linear with a gradient of about $\Delta=0.5$, for the whole range of strain rates, $0.001-100 \mathrm{~s}^{-1}$, with increasing process temperature from 400 to $550{ }^{\circ} \mathrm{C}$, for both true strain values $(0.5$ and 0.9 ). For $500-550{ }^{\circ} \mathrm{C}$ and $\dot{\varepsilon}=0.1 \mathrm{~s}^{-1}$, its value approximated to $2.75 \mathrm{~kJ} /\left(\mathrm{m}^{3} \mathrm{~s}\right)$ and shows almost linear character. This allows a conclusion about the progress of dynamic recrystallization and dynamic recovery (Fig. 6d), where considerable and uniform grain refinement of fibrous structure, as well as large variety of particle and phase precipitates, become evident. It should be noted that at $500{ }^{\circ} \mathrm{C}$ and strain rates of $0.001,1$ and $10 \mathrm{~s}^{-1}$ dynamic recrystallization and dynamic recovery did not take place.

It was found that the temperature of plastic deformation and the strain rate significantly influence the occurrence of 
banding in the microstructure; compare the microstructures of Fig. 6g, h with e, f (deformed bands can be observed curved in accord with the deformation of side surface of the compression specimen). The banding, for strain rate of $1 \mathrm{~s}^{-1}$, results from the high advancement of recrystallisation processes within some of the bands and a lack of them within others. In the bands where recrystallisation took place (the material's microstructure was homogenised), this resulted, most probably, in a decrease of $J$ co-content. For the strain rate of $10 \mathrm{~s}^{-1}$, the developed microstructure indicated a high advance of recovery processes with less evident recrystallization effects, compared to a lower strain rate. At the boundaries of fibres and primary grains, the processes of bulging and separating of fine grains from a fibrous structure are initiated. The addition of $0.1 \% \mathrm{Zr}$ contributes to the formation of fine-grained dispersed phase $\beta^{\prime}\left(\mathrm{Al}_{3} \mathrm{Zr}\right)[2,3$, 40], thus affecting the grain size and facilitating the nucleation of $\theta^{\prime} / \delta^{\prime}$ precipitates. At the relatively high process temperature of $400-500{ }^{\circ} \mathrm{C}, \delta^{\prime}\left(\sim \mathrm{Al}_{3} \mathrm{Li}\right)$ precipitates are resistant to growth and additionally contribute to the dispersion hardening of the alloy, at the same time hindering the dynamic recrystallization. Manganese is added to form $\mathrm{Al}_{20} \mathrm{Cu}_{2} \mathrm{Mn}_{3}$ incoherent dispersoids, which help to control grain size and texture evolution $[2,3]$. The microstructure for the strain rate $0.1 \mathrm{~s}^{-1}$ (Fig. 6c, d) indicates strong grain refinement, and in connection with a stable $J$ co-content component and convergence of the increase of a parameter of power dissipation efficiency, proceeding of recrystallization, recovery and microstructure homogenization processes. It can be observed that the recrystallization and recovery processes had proceeded already, before the deformation process was finished. The microstructure is then characterized by uniform fine grains with numerous precipitates. Literatures [2-6, 41-43] indicate that, except the precipitates of $\beta^{\prime}$ $\left(\mathrm{Al}_{3} \mathrm{Zr}\right)$ and $\theta^{\prime} / \delta^{\prime}$ particles hardening the alloy and being coherent with the matrix, the intermetallic phases: $\mathrm{T}_{1}$ $\left[\mathrm{Al}_{2}(\mathrm{Cu}, \mathrm{Li}-\mathrm{Mg})\right]$ and $\mathrm{T}_{2}\left(\mathrm{Al}_{6} \mathrm{CuLi}_{3}\right)$ were identified at grain boundaries. In the case of strain rate of $0.001 \mathrm{~s}^{-1}$, the decay of banded structure is evident. The effects, attributed to plastic deformation of already recrystallized regions, can also be observed.

The efficiency of power dissipation, $\eta$, as the measure of material's workability, was determined using the formula proposed by Prasad et al. [28] for DMM model:

$\eta=\frac{J}{J_{\max }}=\frac{2 m}{m+1}$,

where $J$ is dissipator co-content (component related to power dissipation through structural changes, e.g. dynamic recrystallization, dynamic recovery and grain growth) (Eq. (6)), $J=J_{\max }=\frac{P}{2}=\frac{\sigma \dot{\varepsilon}}{2}$ for the ideal linear dissipator $(m=1), m$ is strain rate sensitivity exponent.
The strain rate sensitivity exponent $(m)$ is a key parameter defining the relative (not absolute) partitioning of power between heat generation and microstructural changes [25].

The maximum value of $\eta$ indicates the possibility of realisation of highly efficient plastic working. Figure 7 presents the variations of $\eta$ with temperature, for true strains of 0.5 and 0.9 .

The actual values of the parameter of power dissipation efficiency $\eta$ were determined basing on the curves describing the variations of strain rate sensitivity exponent $m$ (Fig. 4). The curves of power dissipation form broken lines in which the peak of power dissipation occurs for different strain rates. Their character is similar for strains $\varepsilon=0.5$ and 0.9 , differing however in the fact that for strain amounting to 0.9 all the curves obtained for the temperature of $500{ }^{\circ} \mathrm{C}$ form a characteristic convergence of the values of $\eta$ parameter, in the range of (33-31)\%, for the strain rate range of 0.001-10 $\mathrm{s}^{-1}$. In case of the strain rate of $100 \mathrm{~s}^{-1}$, the parameter $\eta$ slightly decreases in the whole range of temperatures $\left(400-550{ }^{\circ} \mathrm{C}\right)$, staying in the range of (37-32)\%. It can be observed in Fig. $7 \mathrm{~b}$, for the temperature of $500{ }^{\circ} \mathrm{C}$, that the peak in the convergence of $\eta$ parameter occurs at $36 \%$ for the strain rate of $0.001 \mathrm{~s}^{-1}$, and the lowest level is $\eta=27 \%$ for the strain rate of $1 \mathrm{~s}^{-1}$. For the alloy under investigation (AA2099), it can be assumed that the maximum value of $\eta=36 \%$ determines the highest workability at the process temperature of $500{ }^{\circ} \mathrm{C}$. At this temperature, the actual values of $\eta$ parameter are as follows: $31.5 \%$ for $\dot{\varepsilon}=0.01 \mathrm{~s}^{-1}$ and $28.5 \%$ for $\dot{\varepsilon}=0.1 \mathrm{~s}^{-1}$. Highly regular convergence of the power dissipation efficiency coefficient $(\eta)$ with uniform slope of curves, for strain rates of 0.001 and $1 \mathrm{~s}^{-1}$ (Fig. 7b), gives the best recommendation for plastic working of AA2099 alloy and for obtaining the internal material features, i.e. microstructure evolution, homogeneity and fine-grained character, as influenced by inducing strains. Such uniformity of the convergence of curves (Fig. 7a), for strain rates of 0.001 and $1 \mathrm{~s}^{-1}$, is not observed in case of strain of 0.5 . It can be stated that the optimization of plastic working conditions for this alloy is most favourable considering the selected process parameters (temperature, strain rate and strain). This is confirmed by the observation of microstructure at the temperature of $500{ }^{\circ} \mathrm{C}$ (Fig. 6). Li et al. [11] present the analysis of optimum plastic working of $\mathrm{Al}-\mathrm{Cu}-\mathrm{Mg}-\mathrm{Mn}-\mathrm{Zr}$ alloy in rolling, extrusion and forging processes, at the temperature of $390-420{ }^{\circ} \mathrm{C}$ and strain rate of $0.1-1 \mathrm{~s}^{-1}$, for true strain of 0.5 . Within this range of process parameters, the researchers observed a peak in the convergence of coefficient $\eta=27 \%$, indicating the best workability of the alloy. The convergence of power dissipation efficiency coefficient, analysed by Prasad et al. [28] for Ti $(\alpha+\beta)$ alloy classified as Ti-6-2-4-2, indicated the occurrence of the peak at the temperature of $927{ }^{\circ} \mathrm{C}$ and strain rate of $0.001 \mathrm{~s}^{-1}$, connected with specific microstructural changes 

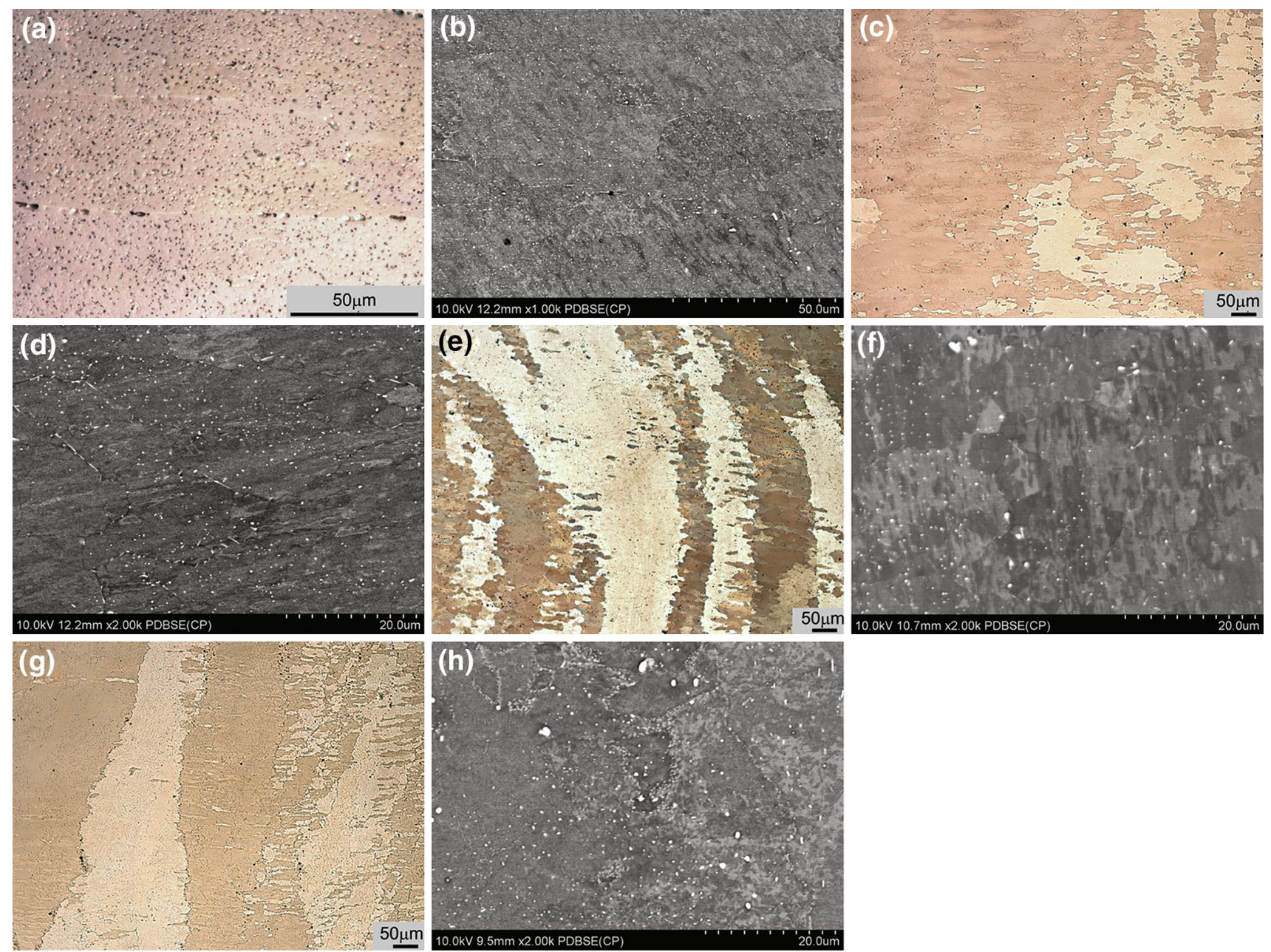

Fig. 6 Optical a, $\mathbf{c}, \mathbf{e}, \mathbf{g}$ and SEM b, d, f, h microstructures of AA2099 alloy after deformation in isothermal conditions in uniaxial compression test, at the temperature of $500{ }^{\circ} \mathrm{C}$ and strain rate of: $\mathbf{a}, \mathbf{b} \dot{\varepsilon}=0.001 \mathrm{~s}^{-1}, \mathbf{c}, \mathbf{d} \dot{\varepsilon}=0.1 \mathrm{~s}^{-1}, \mathbf{e}, \mathbf{f} \dot{\varepsilon}=1 \mathrm{~s}^{-1}, \mathbf{g}, \mathbf{h} \dot{\varepsilon}=10 \mathrm{~s}^{-1}$, for true strain of 0.9

and energetic aspect of the process, thus giving grounds for the increase of plastic working efficiency with increasing value of $\eta$ parameter. The elaborated results of investigations for the alloy Ti $(\alpha+\beta)$ : Ti-6Al-2Sn-4Zr-2Mo (Ti-6-2-4-2) technologically signify the establishing of optimum conditions for hot plastic working and reveal that the accumulated high plastic deformation energy potential undergoes the distribution in the material evenly, to the uniform flow and to the heat of plastic deformation. The presented results of investigations [28], though concerning the alloys other than AA2099, raise no doubts regarding the recommended process parameters, with adequately stable thermal conditions of plastic working determined using DMM method. Lin et al. [32] developed, for $\mathrm{Al}-\mathrm{Zn}-\mathrm{Mg}-\mathrm{Cu}$ alloy (7075 aluminium alloy), the $P$-maps and stated that with the increase of strain, the instability domains in processing maps increase. The optimum hot working domains were established for the reasonable dynamic recrystallization in temperature range of $350-450{ }^{\circ} \mathrm{C}$ and strain rates range of $0.001-0.05 \mathrm{~s}^{-1}$ (a peak of efficiency of 29.5\%). Yin et al. [38] analysed the hot deformation behaviour of an $\mathrm{Al}-\mathrm{Cu}-\mathrm{Li}$ alloy by applying isothermal compression test using Gleeble 3500 thermomechanical simulator in the temperature range of $300-500{ }^{\circ} \mathrm{C}$ and strain rate range of $0.01-10 \mathrm{~s}^{-1}$, at the strains of 0.3-0.8. Two peak efficiency domains were exhibited, at $300-350{ }^{\circ} \mathrm{C}$ and $0.01-0.03 \mathrm{~s}^{-1}$ and at $450-500{ }^{\circ} \mathrm{C}$ and $0.01-0.1 \mathrm{~s}^{-1}$. According to microstructural observation, the dynamic recrystallization took place in the temperature range of $400-500{ }^{\circ} \mathrm{C}$ and strain rates of $0.01-0.1 \mathrm{~s}^{-1}$. The significant effect of strain on the peak efficiencies was found and, additionally, it was proved that the peak efficiency of power dissipation increased almost linearly with increasing strain. Therefore, the peak efficiency reflects precisely the characteristic of a material subjected to plastic working under strict process parameters (temperature, strain rate and strain).

The regions where metallurgical instability of the process during plastic deformation may be observed [30, 31], can be correctly identified when

$\frac{\mathrm{d} D}{\mathrm{~d} \dot{\varepsilon}}<\frac{D}{\dot{\varepsilon}}$ 

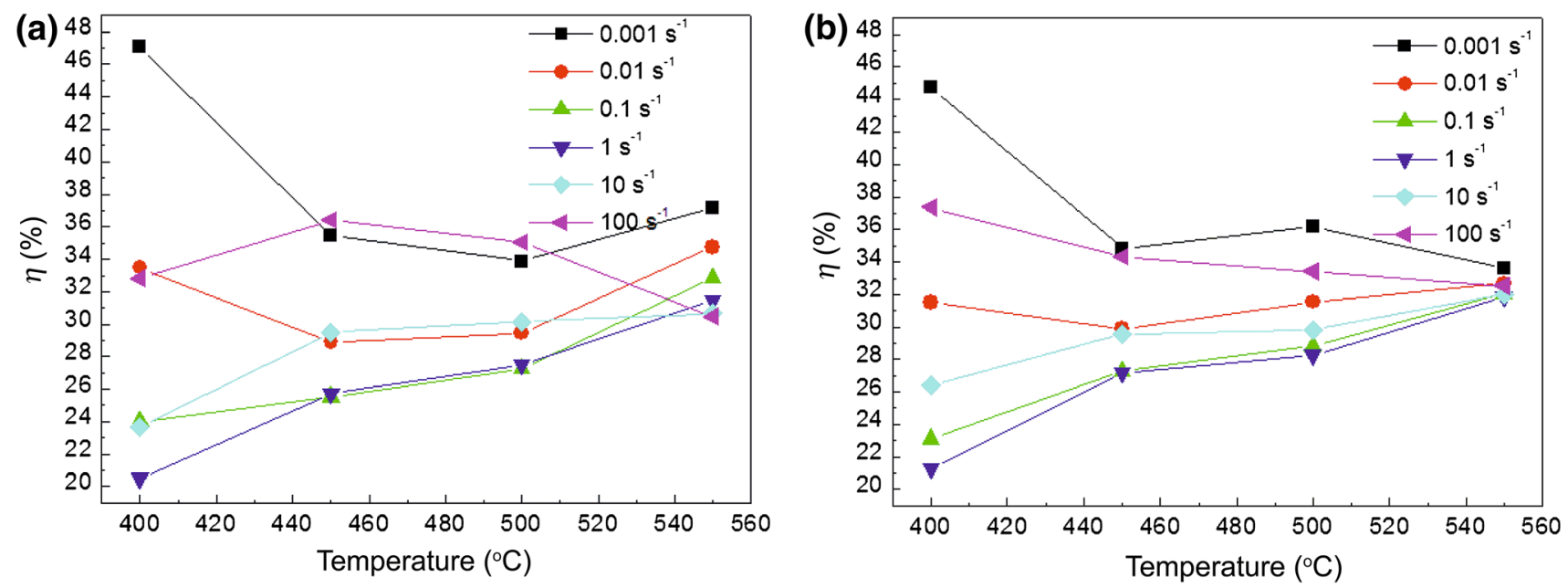

Fig. 7 Variations of power dissipation efficiency, as a function of forging temperature and strain rate, for constant strain value of 0.5 a and $0.9 \mathbf{b}$

where $D$ is dissipation function at given temperature, $\dot{\varepsilon}$ is strain rate, $\mathrm{s}^{-1}$.

Using DMM, it is assumed that $D$ component corresponds to $J$ co-content component (Eq. (6)) and Eq. (9) can be written as $[30,39]$ :

$\frac{\mathrm{d} J}{\mathrm{~d} \dot{\varepsilon}}<\frac{J}{\dot{\varepsilon}}$.

After mathematical transformations of Eq. (6) [30, 31] and considering Eq. (9), on the basis of the extremum principles of irreversible thermodynamics as applied to large plastic deformation [9, 29], a criterion is obtained which makes it possible to identify the flow instability of the alloy during hot working

$\xi(\dot{\varepsilon})=\frac{\partial \log \left(\frac{m}{m+1}\right)}{\partial \log \dot{\varepsilon}}+m$

It is assumed $[9,11,29,30,33,35,37]$ that if the parameter $\xi \leq 0$, the microstructural instability of material flow occurs (adiabatic shear bands, flow localization, dynamic strain ageing, Lüders bands, kink bands, mechanical twinning, flow rotations). The parameter $\xi$ is considered to be an important warning when designing the technology of plastic working for a specific material. Variations of $\xi$ with strain rate and temperature make it possible to plot instability maps.

Figure 8 presents the processing maps, which enable the optimization of hot working technology, allowing to precisely determine the process parameters. The complex P-map is described as follows: the value of power dissipation coefficient $\eta$ expressed in \%-solid black isoclines; the parameter $\xi \gg 0$ reflecting the absence of localization of structural instability region-broken red isoclines; "I"- - domain of highest efficiency (process optimum), solid black contour line; "II"domain of high efficiency, solid black contour line; (1), (2), (3) - process frames, dotted black contour lines. The analysis of plastic deformation process efficiency and the parameter defining the material flow instability regions showed full stability of flow for the AA2099 alloy. The research [41] carried out for $\mathrm{Al}-\mathrm{Zn}-\mathrm{Mg}-\mathrm{Cu}-\mathrm{Zr}$ complex alloys, known as 7056 and 7150 , allowed the establishment of the optimum plastic working conditions for rolling process, i.e. the temperature of $390-420{ }^{\circ} \mathrm{C}$ and strain rate of $0.001-0.01 \mathrm{~s}^{-1}$. This can be comparatively related to the determined two domains (regions) one of high and the other of the highest efficiency of $\eta$ for the AA2099 alloy (Fig. 8). The so-called process efficiency frames were separated from these domains. The characters of isoclines and domains for true strains of 0.5 and 0.9 are very similar, with differences concerning only the determined values. In Fig. 8a, for true strain of 0.5 , the so-called process efficiency frames separated from domains (regions of maximum efficiency) were plotted only for comparison. The domain I of the highest process efficiency (with $\eta=(23.6-34.7) \%$ and $\xi=0.20-0.32$, in the temperature range of $400-523{ }^{\circ} \mathrm{C}$ and for strain rates of 2-100 $\mathrm{s}^{-1}$ ) may be recommended for the design of technology of die forging in conventional conditions. Two process efficiency frames are located in the domain $\mathrm{I}$ :

(1) The frame (1) of maximum power dissipation efficiency $\eta=(30-35) \%$ and the parameter $\xi=0.24$ 0.30 , in the temperature range of $415-450{ }^{\circ} \mathrm{C}$ and for strain rates of 10-100 s $\mathrm{s}^{-1}$ (completed by the parameter $m=0.23-0.20$ (Fig. 4) and $J$ co-content component, $J=6.5 \mathrm{~kJ} /\left(\mathrm{m}^{3} \mathrm{~s}\right)$, of constant linear character, Fig. 5).

(2) The frame (2), located beside the frame (1), also of maximum power dissipation efficiency $\eta=(30.9-$ $33.0) \%$ and the parameter $\xi=0.20-0.25$, in the temperature range of $465-523{ }^{\circ} \mathrm{C}$ and for strain rates of $50-100 \mathrm{~s}^{-1}$ (completed by the parameter $m=$ 0.23-0.20 (Fig. 4) and $J$ co-content component, $J=6.1-6.0 \mathrm{~kJ} /\left(\mathrm{m}^{3} \mathrm{~s}\right)$, of descending linear character, Fig. 5). 

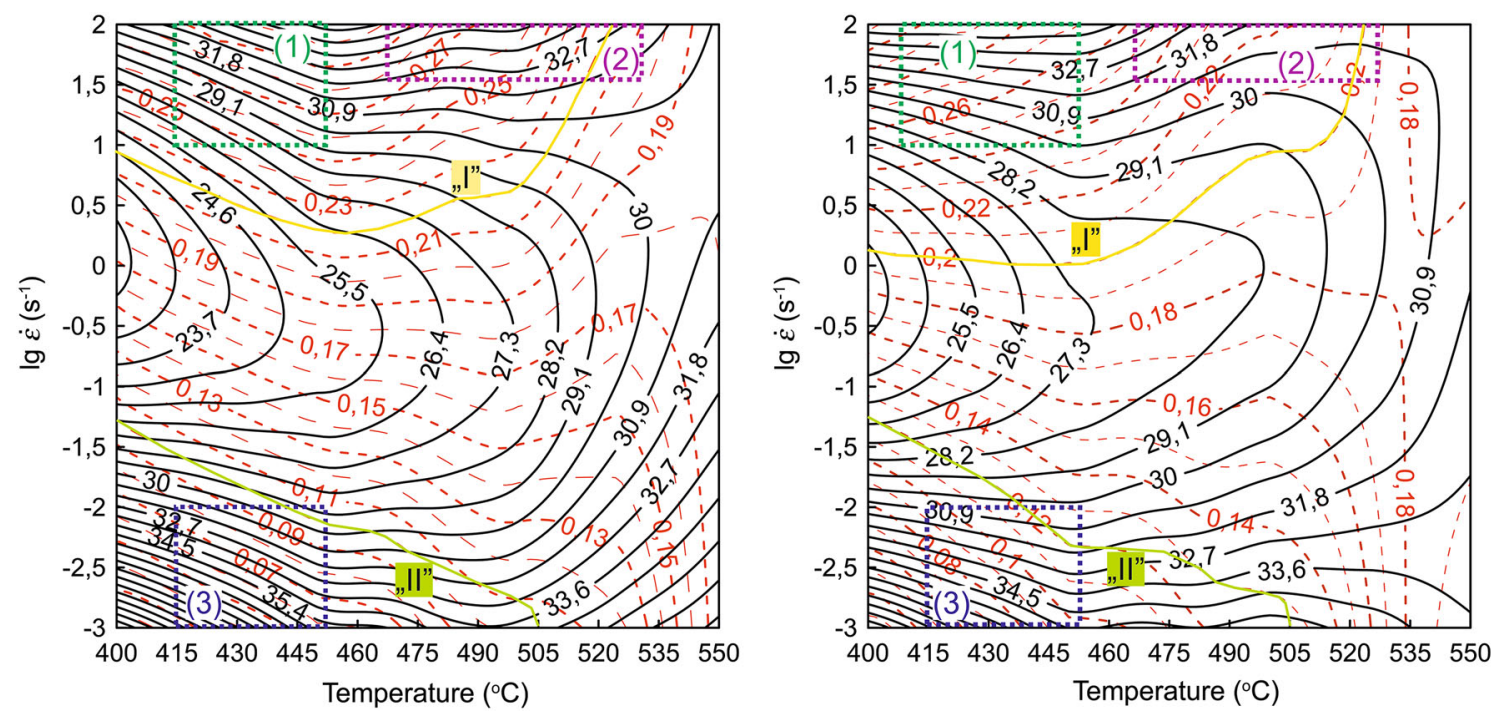

Fig. 8 Complex map of power dissipation efficiency and flow instability parameter, for AA2099 alloy, as a function of strain rate and temperature, for true strain of $0.5 \mathbf{a}$ and $0.9 \mathbf{b}$

The domain II of high process efficiency (with $\eta=(26.4-35.5) \%$ and $\xi=0.12-0.02$, in the temperature range of $400-484{ }^{\circ} \mathrm{C}$ and for strain rates of $0.13-0.001 \mathrm{~s}^{-1}$ ) may be recommended for the design of technology of die forging in high-plasticity and isothermal conditions. The process efficiency frame (3) was located within this domain, defined by very high power dissipation efficiency $(\eta=(31.0-40.5) \%)$ and the parameter $\xi=0.05-0.13$, in the temperature range of $415-450{ }^{\circ} \mathrm{C}$ and for strain rates of $0.01-0.001 \mathrm{~s}^{-1}$ (completed by the parameter $m=0.205-0.30$ (Fig. 4) and $J$ co-content component, $J=0.75-0.5 \mathrm{~kJ} /\left(\mathrm{m}^{3} \mathrm{~s}\right.$ ), of descending linear character, Fig. 5).

The extended analysis of a character of convergence of power dissipation efficiency coefficient $(\eta)$ (Fig. 7) is fully fixed in a complex map (Fig. 8). Figure 7 implies the best process parameters for a complex process efficiency map $(\eta)$, with the parameter $\xi \gg 0$ (Fig. 8), in two established process efficiency domains. The instability of plastic flow in uniaxial compression as well as its localization is strongly connected with deformation conditions. In case of the analysed alloy, the process instability was excluded (considering the values of $\xi$ parameter). Moreover, it is assumed that during compression of specimens of $\mathrm{Al}-\mathrm{Cu}-$ $\mathrm{Li}$ and other alloys, the beginning of instability is a strain localization occurring within the individual grains, which was not observed in the microstructure (Fig. 6). At the temperature of $500{ }^{\circ} \mathrm{C}$ (peak of convergence of power dissipation coefficient), the industrial tests (Belos-PLP in Bielsko-Biała, Poland) of single-operation forging of a high-current contact tip (Fig. 9) used in power engineering were realised using screw press of $20 \mathrm{~kJ}$ maximum striking energy and $450 \mathrm{~mm} / \mathrm{s}$ maximum velocity. It was shown

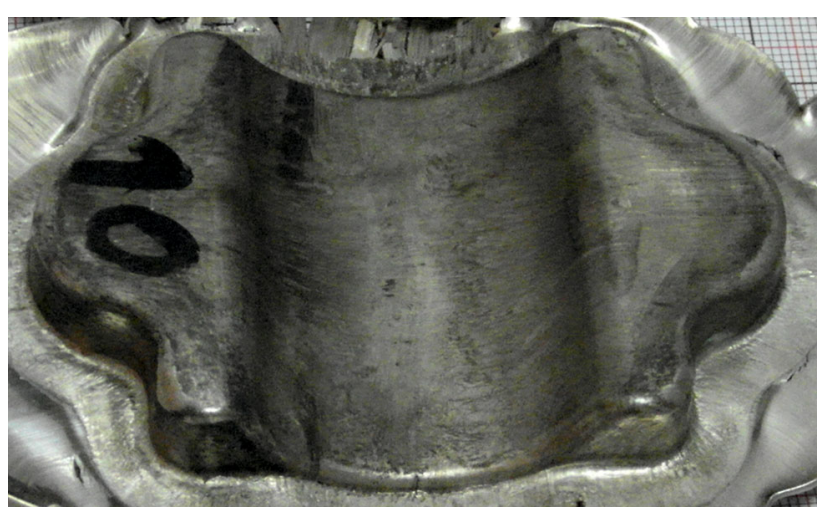

Fig. 9 Shape of the final forging of a contact tip

that within the parametrically specified process efficiency frame (2), there is a possibility of obtaining high-quality forging showing the proper microstructure and high level of HV microhardness. The AA2099 alloy is highly sensitive to the temperature of plastic working process. Therefore, it requires a strict regime to be followed during heating of the material before forging.

\section{Conclusions}

The optimum parameters (as for computational engineering and analyses) of the thermomechanical plastic working process, in structural energetic quantification, for the AA2099 alloy were determined. The combination of classical methods of material's workability testing, such as tensile test and uniaxial compression test, with a DMM method, was applied to the complex analysis of hot working 
processes. A practical comprehensive approach was created for the precise localisation of the range of process parameters: temperature, strain rate and strain, on the basis of the analysis of the following parameters: $m, J$ co-content, power dissipation efficiency $(\eta \%)$ and process instability $(\xi)$. The analysis of hot working technology results in a recommendation for the AA2099 alloy, which is concerned of three process efficiency frames, denoted as (1)-(3), relating to the design of correct and effective realisation of the technology. The process frames formulate the recommendations for the following processes: conventional die forging - the frames (1) and (2), and die forging in high-plasticity and isothermal conditions (with the condition of $m \geq 0.3$ decisive for superplasticity) - the frame (3). On the basis of computational engineering, the conditions were comprehensively specified for the realisation of hot die forging process, in relation to the microstructure, and constitutive relationships between the mechanical state and microstructural changes were defined. The increased ductility in hot die forging will allow the achievement of high technical and functional quality of final forgings. Moreover, it was found that the convergence of power dissipation passing through the peak (Fig. 7) at the temperature of $500{ }^{\circ} \mathrm{C}$, is important, defining thermal system principles and the optimum parameters of plastic working. There the energetic components of the process undergo even distribution into uniform material flow and heat of plastic deformation. The convergence of power dissipation, along with $J$ co-content component, strongly affects the evolving microstructure as well as the proceeding processes of dynamic recrystallization and recovery.

Acknowledgments Appreciation is also expressed to Prof. A.S. Wronski (University of Bradford, UK) for editing the manuscript. The research project was financed by the Ministry of Science and Higher Education (AGH-UST statutory research project No. 11.11.110.292).

\section{References}

[1] Technical information from Alcoa Inc. (Alcoa Salles Office, June 2007)

[2] C. Giummarra, B. Thomas, R.J. Rioja, in Proceedings of the Light Metals Technology Conference, Canada, 2007

[3] N. Eswara Prasad, A. Gokhale, R.J.H. Wanhill, AluminumLithium Alloys: Processing, Properties, and Applications, 1st edn. (Butterworth-Heinemann, Oxford, 2013)

[4] Y. Lin, Z. Zheng, S. Li, X. Kg, Y. Han, Mater. Charact. 84, 88 (2013)

[5] Y. Lin, Z. Zheng, S. Li, Arch. Civ. Mech. Eng. 14, 61 (2014)

[6] Y. Ma, X. Zhou, G.E. Thompson, T. Hashimito, Mater. Chem. Phys. 126, 46 (2011)

[7] K.I. Wang, S.Q. Lu, M.W. Fu, X. Li, X.J. Dong, Mater. Sci. Eng. A 527, 7279 (2010)

[8] Y.V.R.K. Prasad, S. Sasidhara, Hot Working Guide: A Compendium of Processing Maps (ASM International, Materials Park, OH, 1997)

[9] Y.V.R.K. Prasad, J. Mater. Eng. Perform. 12, 638 (2003)
[10] G.E. Dieter, H.A. Kuhn, S.L. Semiatin, Handbook of Workability and Process Design (ASM International, Materials Park, $\mathrm{OH}, 2003)$

[11] Y. Li, Z. Liu, L. Lin, J. Peng, A. Ning, J. Mater. Sci. 46, 3708 (2011)

[12] F. Sui, L. Xu, L. Chen, X. Liu, J. Mater. Process. Technol. 211, 433 (2011)

[13] M.C. Somani, K. Muraleedharan, N.C. Birla, V. Singh, Y.V.R.K. Prasad, Metall. Mater. Trans. A 25, 1693 (1994)

[14] D. Cai, L. Xiong, W. Liu, G. Sun, M. Yao, Mater. Des. 30, 921 (2009)

[15] M. Karami, R. Mahmudi, Mater. Des. 53, 534 (2014)

[16] T. Kubina, J. Kliber, L. Kunčická, Paper Presented at 22nd International Conference on Metallurgy and Materials METAL 2013, Hotel Voronez I, Brno, Czech Republic, 2013

[17] J. Luo, M. Li, W. Yu, H. Li, Mater. Sci. Eng. A 504, 90 (2009)

[18] C.M. Cepeda-Jiménez, O.A. Ruano, M. Carsí, F. Carreño, Mater. Sci. Eng. A 552, 530 (2012)

[19] A. Jenab, A. Karimi Taheri, Int. J. Mech. Sci. 78, 97 (2014)

[20] G. Jagan Reddy, N. Srinivasan, A.A. Gokhale, B.P. Kashyap, J. Mater. Process. Technol. 209, 5964 (2009)

[21] D. Wen, Y.C. Lin, H. Li, X. Chen, J. Deng, L. Li, Mater. Sci. Eng. A 591, 183 (2014)

[22] V.K. Jain, K.V. Jata, R.J. Rioja, J.T. Morgan, A.K. Hopkins, J. Mater. Process. Technol. 73, 108 (1998)

[23] Y. Yang, Z. Zhang, X. Li, Q. Wang, Y. Zhang, Mater. Des. 51, $592(2013)$

[24] J. Liu, J. Li, Z. Cui, H. Ou, L. Ruan, Trans. Nonferrous Met. Soc. China 23, 3011 (2013)

[25] J. Liu, Z. Cui, C. Li, J. Mater. Process. Technol. 205, 497 (2008)

[26] P.V. Sivaprasad, S. Venugopal, C.H.J. Davies, Y.V.R.K. Prasad, Model. Simul. Mater. Sci. Eng. 12, 285 (2004)

[27] J. Li, J. Liu, Z. Cui, Mater. Des. 56, 889 (2014)

[28] Y.V.R.K. Prasad, H.L. Gegel, S.M. Doraivelu, J.C. Malas, J.T. Morgan, K.A. Lark, D.R. Barker, Metall. Trans. A 15, 1883 (1984)

[29] Y.V.R.K. Prasad, D.H. Sastry, R.S. Sundar, S.C. Deevi, in Proceedings of 3rd International Symposium on Structural Intermetallics (TMS The Minerals, Metals and Materials Society, Warrendale, 2001)

[30] S.V.S.N. Murty, B.N. Rao, Mater. Sci. Eng. A 254, 76 (1998)

[31] S.V.S.N. Murty, B.N. Rao, J. Mater. Sci. Lett. 17, 1203 (1998)

[32] Y.C. Lina, L. Lia, Y. Xia, Y. Jiang, J. Alloys Compd. 550, 438 (2013)

[33] K.P. Rao, Y.V.R.K. Prasad, C. Dharmendra, N. Hortc, K.U. Kainer, Mater. Sci. Eng. A 528, 6964 (2011)

[34] D. Szeliga, J. Gawąd, M. Pietrzyk, J. Comput. Methods Appl. Mech. Eng. 195, 6778 (2006)

[35] Y.V.R.K. Prasad, T. Seshacharyulu, Int. Mater. Rev. 43, 243 (1998)

[36] M.W. Grabski, Nadplastyczność Strukturalna Metali (Biblioteka Fizyki Metali, Wyd. Śląsk, Katowice, 1973)

[37] O. Sivakesavam, Y.V.R.K. Prasad, Mater. Sci. Eng. A 323, 270 (2002)

[38] H. Yin, H. Li, X. Su, D. Huang, Mater. Sci. Eng. A 586, 115 (2013)

[39] S. Ramanathan, R. Karthikeyany, V. Deepak Kumar, G. Ganesan, J. Mater. Sci. Technol. 22, 611 (2006)

[40] Y. Liu, Y. Ning, Z. Yao, H. Guo, J. Alloys Compd. 587, 183 (2014)

[41] H. Zhang, N. Jin, J. Chen, Trans. Nonferrous Met. Soc. China 21, 437 (2011)

[42] H. Li, Y. Tang, Z. Zeng, Z. Zheng, F. Zheng, Mater. Sci. Eng. A 498, 314 (2008)

[43] N.P. Gurao, A.O. Adesola, A.G. Odeshi, J.A. Szpunar, J. Alloys Compd. 578, 183 (2013) 